Fecha de recepción: 2 de marzo de 2020. Fecha de evaluación: 12 de mayo de 2020. Fecha de aprobación: $1^{\circ}$ de julio de 2020.

\section{El gen culpable: imaginarios de justicia y genética en torno al Registro Nacional de Datos Genéticos en Argentina*}

Taly Barán ${ }^{* *}$ Amalia Peralta* ${ }^{\star \star *}$
Para citar este artículo

Barán, T. y Peralta, A. (2020). El gen culpable: imaginarios de justicia y genética en torno al Registro Nacional de Datos Genéticos en Argentina. Vía Iuris, 29, 205-221. DOI: https://doi.org/10.37511/ viaiuris.n29a8.

\title{
RESUMEN
}

La tecnología genética presenta usos cada vez más diversos y extendidos. Sin embargo, son circunstancias muy específicas en las que esta pasa a formar parte de los temas de debate público. Así ocurrió en julio de 2013, en Argentina, con la creación del Registro Nacional de Datos Genéticos de Delitos contra la Integridad Sexual más conocido como "Registro de Violadores". El proceso de aprobación de esta ley abrió espacios de diálogo en los que la genética se erigió como una pieza central del discurso de diversos actores. En este artículo se centra la atención en el análisis de este caso ya que permite abordar a la genética en tanto significante cargado de sentidos sociales en constante transformación. Se parte de una estrategia metodológica cualitativa a partir del análisis de declaraciones públicas y de entrevistas realizadas a actores participantes del debate en torno a la aprobación de la normativa. Se propone reconstruir los imaginarios de genética, violador y justicia que confluyeron en torno a la configuración de esta ley a la vez que se plantean preguntas por los cambios que los usos novedosos de la genética acarrean sobre las concepciones de cuerpo y seguridad. Se concluye que en torno a esta ley es posible encontrar diálogos e intersecciones entre grandes marcos productores de discursos, imaginarios y nuevos dilemas de las sociedades contemporáneas.

* Artículo producido en el marco del proyecto de investigación "Genética y derechos humanos: políticas y gestión de la salud y la identidad en la Argentina reciente (1980-2017)". PIP 11220170100777CO. CEIL-Conicet (Periodo 2019-2020). Buenos Aires (Argentina).

** Doctoranda en Ciencias Sociales (CEIL-CONICET). Magíster en Derechos Humanos y democratización para América Latina y el Caribe(CIEP-UNSAM). Licenciada en Sociología (UBA). Buenos Aires (Argentina) Correo electrónico de contacto: talybaran@gmail.com ORCID. https://orcid.org/0000-0003-1417-2818.

*** Licenciada en Sociología (UBA). Becaria estímulo del Centro Interuniversitario Nacional (CIN). Vinculada al IEALC-Universidad de Buenos Aires. Buenos Aires (Argentina): Correo electrónico: amalia. peralta.1996@gmail.com. ORCID: https://orcid.org/0000-0002-87761026. (Argentina).
DOI: https://doi.org/10.37511/viaiuris.n29a8

Licencia Creative Commons

Esta obra está bajo una Licencia Creative Commons Atribución-NoComercial-Compartirlgual 2.5 Colombia. (c) (1) (2)

\section{Palabras clave}

Violencia sexual; genética; justicia; cuerpo; información; seguridad. 


\title{
The guilty gene: imaginaries of justice and genetics around the National Registry of Genetic Data in Argentina
}

\author{
Taly Barán \\ Amalia Peralta
}

\begin{abstract}
Genetic technology has increasingly diverse and widespread uses. However, there are very specific circumstances in which it becomes part of the topics of public debate. This happened in July 2013, in Argentina, with the creation of the National Registry of Genetic Data of Crimes against Sexual Integrity, better known as the "Registry of Rapists". The process of approval of this law opened spaces for dialogue in which genetics emerged as a centerpiece of the discourse of various actors. This article focuses on the analysis of this case because it allows us to approach genetics as a signifier loaded with social meanings in constant transformation. It is based on a qualitative methodological strategy based on the analysis of public statements and interviews with actors participating in the debate around the approval of the regulation. We propose to reconstruct the imaginaries of genetics, rapist and justice that converged around the configuration of this law, while asking questions about the changes that the novel uses of genetics bring about on the conceptions of the body and security. It is concluded that around this law it is possible to find dialogues and intersections between major frameworks producing discourses, imaginaries and new dilemmas of contemporary societies.
\end{abstract}

Keywords

Sexual violence; genetics; justice; body; information; security. 


\title{
O Gene Culpado: Imaginários de justiça e genética em torno do Registo Nacional De Dados Genéticos Na Argentina
}

\author{
Taly Barán \\ Amalia Peralta
}

\section{RESUMO}

A tecnologia Gene está a tornar-se cada vez mais diversificada e difundida nas suas utilizações. Contudo, há circunstâncias muito específicas em que se torna parte do debate público. Isto aconteceu em Julho de 2013, na Argentina, com a criação do Registo Nacional de Dados Genéticos sobre Crimes contra a Integridade Sexual, mais conhecido como o "Registo de Violadores". O processo de aprovação desta lei abriu espaços de diálogo em que a genética se tornou uma parte central do discurso de vários actores. Este artigo centra-se na análise deste caso porque nos permite abordar a genética como um significante carregado de significados sociais em constante transformação. Baseia-se numa estratégia metodológica qualitativa baseada na análise de declarações públicas e entrevistas com actores que participam no debate em torno da aprovação do regulamento. $\mathrm{O}$ objectivo é reconstruir os imaginários da genética, do violador e da justiça que convergiram em torno da configuração desta lei, ao mesmo tempo que se colocam questões sobre as mudanças que os novos usos da genética provocam nas concepções do corpo e da segurança. Conclui-se que em torno desta lei é possível encontrar diálogos e intersecções entre grandes quadros que produzem discursos, imaginários e novos dilemas nas sociedades contemporâneas.

\section{Palavras-chave}




\title{
Le Gène Coupable : \\ Imaginaires de la justice et de la génétique autour du Registre National Des Données Génétiques En Argentine
}

\author{
Taly Barán \\ Amalia Peralta
}

\begin{abstract}
RÉSUMÉ
Les utilisations du génie génétique sont de plus en plus diverses et étendues. Cependant, il existe des circonstances très spécifiques dans lesquelles elle fait partie du débat public. C'est ce qui s'est passé en juillet 2013, en Argentine, avec la création du Registre national de données génétiques sur les délits contre l'intégrité sexuelle, plus connu sous le nom de "Registre des violeurs". Le processus d'approbation de cette loi a ouvert des espaces de dialogue dans lesquels la génétique est devenue un élément central du discours des différents acteurs. Cet article se concentre sur l'analyse de ce cas car il nous permet d'aborder la génétique comme un signifiant chargé de significations sociales en constante transformation. Elle s'appuie sur une stratégie méthodologique qualitative basée sur l'analyse des déclarations publiques et des entretiens avec les acteurs ayant participé au débat entourant l'approbation du règlement. Il s'agit de reconstruire les imaginaires de la génétique, du violeur et de la justice qui ont convergé autour de la configuration de cette loi, tout en posant des questions sur les changements que les nouveaux usages de la génétique entraînent dans les conceptions du corps et de la sécurité. II est conclu qu'autour de cette loi, il est possible de trouver des dialogues et des intersections entre des cadres majeurs qui produisent des discours, des imaginaires et de nouveaux dilemmes dans les sociétés contemporaines.
\end{abstract}

Mots-clés

Violence sexuelle; génétique; justice; corps; information; sécurité. 


\section{INTRODUCCIÓN}

El futuro ya está aquí - solo está distribuido de forma despareja

\section{William Ford Gibson}

Hace ya muchas décadas que la biología avanza en sus conocimientos en torno a la genética: la transmisión de información hereditaria mediante el ADN. Sin embargo, la genética no se limita a ser meramente un área de estudio científico, sino que, a lo largo de la historia, participó como elemento de múltiples discursos que trascendieron los límites de un laboratorio: la división de la humanidad por razas, las doctrinas eugenésicas y las justificaciones del Holocausto son solo algunos ejemplos.

Por ello se hace crucial abordar la genética desde una perspectiva sociológica. Esto implica no pensarla como mera transmisión de lo biológico, sino entender que los cuerpos no tienen una existencia en el vacío, ya que se encuentran situados en determinados contextos. Cuando hablamos de células, sangre, genes, ya estamos considerando aún sin tener consciencia de ello- determinadas "verdades" científicas que no son ajenas a la lógica de lo social. Inclusive las preguntas que cada comunidad científica se hace en torno a estos temas son habilitadas por determinadas sensibilidades $y$ preocupaciones sociales, y estas ya preconfiguran los posibles hallazgos o desarrollos.

Al respecto, Argentina presenta una trayectoria particular asociada al uso de la genética que la diferencia de otras experiencias internacionales. En el marco de la búsqueda por la restitución de hijos e hijas de desaparecidos durante la última dictadura militar, se creó en 1987 el Banco Nacional de Datos Genéticos. Esta experiencia situó al caso argentino en escena mundial a partir del uso del ADN de un modo que para entonces resultó novedoso: como portador "material" de la búsqueda de justicia y reparación de las violaciones de derechos por parte del Estado. Para Penchaszadeh (2018), esta experiencia, con fuerte impacto en la esfera pública, promovió la creación de un imaginario social local que asocia fuertemente la genética y los derechos humanos.

Sin embargo, el uso de esta tecnología en Argentina no se circunscribe exclusivamente al campo de los derechos humanos. En la actualidad, y de la mano de los desarrollos de la ciencia y la técnica, la genética aparece como un elemento que atraviesa la cotidianidad de maneras diversas, con más o menos visibilidad pública. Por dar un ejemplo, Argentina es el tercer productor mundial de organismos genéticamente modificados (solo después de Estados Unidos y Brasil) según los datos del Servicio Internacional de Adquisición de Aplicaciones de Agrobiotecnología (ISAAA, 2016, p. 3). El 90 \% de la soja que se produce en el país está modificada genéticamente, así como el 70 \% del maíz y el 60 \% del algodón. Desde el año 2003, el equipo de investigación de la Facultad de Agronomía de la Universidad de Buenos Aires desarrolló los primeros bovinos transgénicos de América Latina, y en la actualidad una serie de empresas argentinas se dedican comercialmente a ello ${ }^{1}$.

A pesar de lo extendido que parece el uso de la genética, son circunstancias muy específicas en las que esta pasa a formar parte de los temas de agenda. Es por esto que se tornan ricos e interesantes aquellos momentos en los que invade el debate público. En julio de 2013 fue sancionada la Ley 26.879, a raíz de la cual se creó el Registro Nacional de Datos Genéticos de Delitos contra la Integridad Sexual (RNDG), más conocido como "Registro de Violadores". El proceso de aprobación de esta ley abrió espacios de diálogo en los que la genética se erigió como una pieza clave del discurso de diversos actores. El interés del caso de estudio radica, además, en que no ha sido suficientemente tematizada en el país la relación entre los discursos genéticos y la "razón securitaria y sus traducciones técnicas" (Gatti y Anstett, 2018, p. 4).

En este artículo centrará la atención en el análisis del "Registro de Violadores" como caso que permite pensar la genética en tanto significante cargado de sentidos sociales en constante transformación. A su vez, los discursos en torno al Registro permiten encontrar diálogos e intersecciones entre grandes marcos productores de discursos: la ciencia y su construcción del cuerpo, la seguridad como política de Estado, la tecnología como productora de objetividad y la dimensión moral para la sexualidad.

Se procederá a reconstruir el contexto de surgimiento del Registro, los actores que lo impulsaron y se

1 Para más información consultar https://www.biosidus.com. $\underline{\text { ar/acerca-de-biosidus.html }}$ 
indagará en los imaginarios que lo prefiguraron, es decir, aquellos elementos diversos que confluyeron en su emergencia. A su vez, se preguntará acerca de aquellos debates e intrigas que este uso de la genética abre, los nuevos dilemas frente a los que las sociedades contemporáneas se encuentran enfrentadas y las viejas categorías que son puestas en cuestión y pierden su calidad axiomática.

Se presentarán, en primer lugar, algunas precisiones metodológicas. En segundo lugar, un breve recorrido por el contexto de emergencia del Registro Nacional de Datos Genéticos de Delitos contra la Integridad Sexual (a partir de aquí RNDG). En tercer lugar, se recuperarán los imaginarios en torno a la genéti$\mathrm{ca}$, la figura de violador y de justicia que pueden reconstruirse a partir del testimonio de diferentes actores implicados en el debate. En cuarto lugar, se abordarán algunas categorías que se encuentran desafiadas por el uso actual de la genética. Para culminar, se presentan algunas reflexiones finales.

\section{METODOLOGÍA}

Se consideró necesario desarrollar una estrategia de investigación cualitativa a partir de la elaboración y el análisis de entrevistas, una técnica de producción de datos que puede utilizarse para conocer la perspectiva de actores sociales. De acuerdo con Sautu (2006), esta técnica permite, en el marco de una interacción flexible, personalizada y espontánea, indagar más en profundidad y alcanzar una mayor riqueza a partir de las palabras y las interpretaciones de los entrevistados. Es posible obtener, de esta forma, no solo una respuesta directa a requerimientos específicos planteados por preguntas cerradas, sino también la emergencia de nuevas categorías posibles de análisis y reflexión.

Para la confección de este artículo se han realizado entrevistas en profundidad a actores claves que participaron y participan en los debates en torno a la creación y el funcionamiento del RNDG. Para ello se han entrevistado a activistas e impulsores del Registro, así como también a personal científico asociado al desarrollo tecnológico en el ámbito de la genética y al creador del primer software pensado para el RNDG ${ }^{2}$. Por otro lado, se ha realizado un

2 Todos los entrevistados fueron debidamente informados sobre el uso que se daría a lo conversado y dieron su consentimiento sobre la escritura de un artículo al respecto. De todos modos, se ha decidido anonimizar los testimonios en los casos que relevamiento de declaraciones públicas del actual presidente del Registro, Jorge Dotto, y de la Ministra de Seguridad de la Nación, Patricia Bullrich.

\section{RESULTADOS Y DISCUSIÓN}

\section{Contexto de surgimiento e implementación del "Registro de violadores"}

La creación del RNDG fue aprobada en julio 2013 por la Cámara de Diputados con previa votación en el Senado. Su reglamentación se dictamina un poco más de cuatro años después, en agosto de 2017. Dicha ley estipula la creación de este Registro con el fin de: "facilitar el esclarecimiento de los hechos que sean objeto de una investigación judicial en materia penal vinculada a delitos contra la integridad sexual" (Ley 26.879) y establece su funcionamiento como un banco de datos en el cual se almacena información genética tanto de personas condenadas por delitos contra la integridad sexual como información proveniente de material genético recolectado como evidencia en el marco de una investigación judicial. Con el fin de poder cotejar una gran cantidad de datos almacenados, se crean perfiles genéticos a partir de la codificación de determinados marcadores específicos del ADN.

La aprobación de esta ley, que da lugar a la creación del Registro, debe entenderse desde la trayectoria y militancia de determinados actores que logran pugnar sus experiencias o su moral e intervenir en casos de fuerte permeabilidad social.

[...] todos los largos años anteriores fueron de idas y venidas y que no había quórum y que le había dado media sanción diputados (porque entra por cualquier cámara, diputados o senadores, lo aprueba uno o lo aprueba el otro) iban pasando los años y perdía el Estado parlamentario, fueron años muy duros. Y cada vez que aparecía una nueva víctima de violación y el violador era reincidente nos daba más la razón. (Isabel Yaconis, 2019, min. 3:34)

Las anteriores son palabras de Isabel Yaconis, integrante la Asociación Civil Madres del Dolor y una de las principales activistas impulsoras del

los datos personales de los entrevistados no aporten mayor claridad a los objetivos de esta investigación. 
Registro; Isabel es madre de Lucila, una joven de 16 años que fue asesinada en el año 2003 resistiendo un intento de violación. El responsable se dio a la fuga, dejando material biológico en el cuerpo de su hija. Desde ese hecho, Isabel comenzó una cruzada activa en busca de esclarecer el crimen y encontrar al asesino de su hija, quien aún no ha sido identificado. A partir de su experiencia personal, y en el marco de la Asociación Madres del Dolor, Isabel y sus compañeras asesoran y acompañan a numerosas familias que se encuentran en situaciones similares. Introduce la historia de la aprobación de una ley como un camino largo de muchos años entre modificaciones, debates y "cajoneo" en los canales internos del Congreso de la Nación, tiempo en el cual se fue interiorizando y pujando por la utilización de la genética en el esclarecimiento de delitos contra la integridad sexual, militancia que sostiene hasta el presente.

Si bien ya existían diversas experiencias internacionales y provinciales dentro de la Argentina de "registros de violadores", los debates parlamentarios en torno a la Ley 26.879 pueden enmarcarse en un contexto de visibilización creciente de las problemáticas en torno a la violencia contra las mujeres. En Argentina, el movimiento feminista adquirió una gran fuerza, lo que se vio reflejado en fenómenos tales como las múltiples movilizaciones convocadas bajo las consignas: "Ni una menos", el "Paro internacional de mujeres" o diferentes marchas y campañas en redes sociales.

Durante estos años, diferentes movimientos y organizaciones sociales avanzan en la visibilización de los casos de violencia y la producción de cifras en torno a esta problemática. Los medios de comunicación masiva aportaron en la difusión y, en algunos casos, espectacularización, sobre todo de determinados casos de jóvenes asesinadas que conmocionaron al país. Se instala, a partir de la conjunción de estos elementos, el debate público sobre la capacidad de las instituciones estatales para dar respuesta a este fenómeno.

Dos casos de violencia sexual aparecen como elementos ineludibles para narrar la trayectoria institucional de la creación y aprobación del Registro. Ambos, con gran impacto público, apresuran los resultados de los debates que llevaron a la aprobación de la ley y su reglamentación. El primero de ellos es el de Ángeles Rawson ${ }^{3}$, joven de 16 años que en junio de 2013 fue atacada sexualmente y asesinada en su intento de resistir a la violación. La víctima era una joven que fue construida por los medios de comunicación como portadora de una moralidad y una conducta ejemplar (buena estudiante, tímida, sin "vicios", que residía en una zona de clase media alta de la capital del país). Esas fueron solo algunas de las características resaltadas por medios masivos de comunicación en un trabajo de construcción de una "buena víctima"4 merecedora de empatía. Un mes después de transcurrido este femicidio, la Cámara de Diputados aprobó la creación del RNDG.

El otro caso en cuestión es el de Micaela García, ocurrido en 2017. Este también presentó un amplio tratamiento mediático, y si bien se retomó el tratamiento de la condición de "buena víctima", esta vez el foco mediático se centraba en una particularidad: el asesino se encontraba preso por dos violaciones anteriores y asesinó a Micaela en el contexto de la concesión de una salida transitoria por buena conducta al interior de la cárcel. Este caso dinamizó la reglamentación del RNDG luego de que su tratamiento haya estado suspendido durante casi cuatro años.

La legislación en cuanto a cómo armar un banco de datos genéticos se hace medio a los golpes: hay un caso mediático, el Congreso dice "uy, tenemos que hacer algo, tenemos que hacer algo", y sale una ley que cuando la ves para atrás, ayy... (Entrevista 2, 2019, $\min$. 36:07)

Así relata el doctor en Física desarrollador del software GENis, motor de búsqueda de coincidencias genéticas empleado por equipos argentinos de diversas universidades, específicamente para

3 Una estrategia adoptada por el movimiento de DD. HH. de larga trayectoria en la Argentina, y que es retomada por el movimiento feminista con más centralidad desde el $\mathrm{Ni}$ una menos, que busca dar visibilidad a las víctimas de femicidio inundando el espacio público con nombres e imágenes de las víctimas. En ese sentido, sus nombres, sus historias de vida y sus rostros aparecen en carteles en marchas y murales, dan nombre a plazas, festivales, centros culturales y leyes. Esta estrategia de visibilización de los hechos de violencia busca que las víctimas de violencia se conviertan en figuras públicas que funcionan como íconos catalizadores de la lucha por los derechos.

4 Numerosas autoras explican los dispositivos de construcción de "buenas y malas víctimas" y las posibilidades diferenciales de que las violencias sean creídas, sentidas y lloradas colectivamente. Para un análisis más profundo ver Hercovich, 2000; Despentes, 2013; Arduino, 2014; Silvestri, 2017; Gil, 2017. 
funcionar como motor de búsqueda para el RNDG. Finalmente, este software fue reemplazado por la incorporación de otro, el Codis ${ }^{5}$. En la actualidad, ambos softwares (Codis-GENis) son utilizados (según cada legislación provincial) y no comparten bases de datos entre sí, reforzando la idea presentada por el entrevistado de las reacciones improvisadas ante los temas de agenda.

La premura en la creación del RNDG luego de años de "cajoneo" — como lo denominó Yaconis - se entiende como reacción institucional a la creciente visibilización y clamor colectivo en torno a los casos de violencia sexual. En su propio decreto de reglamentación estipula:

La ocurrencia de la violencia sexual, -que incluso puede terminar en la muerte de la víctima-, se traduce en un clamor a los poderes públicos para la búsqueda e implementación de medidas que puedan facilitar la identificación de quienes los hayan ejecutado. (Decreto 522/2017, 2017, párr. 4)

La visibilidad pública lograda por determinados casos hace irrumpir, con fuerza, alternativas que Ileana Arduino (2018) denomina como "demagogia punitiva", respuestas de determinados actores institucionales con mucha cobertura mediática que exhiben con orgullo más castigos, nuevos delitos, penas mayores, encierros carcelarios indefinidos, despliegue de nueva tecnología para vigilar y castigar, es decir, el recrudecimiento de las respuestas securitarias. Como explica la autora, el "ensañamiento simbólico con el victimario" opera como evasión de la desatención a las demandas más profundas del movimiento feminista.

En sintonía con lo planteado por Arduino, están las palabras de Jorge Dotto, Director del Registro Nacional de Datos Genéticos Vinculados a Delitos contra la Integridad Sexual. En su discurso, la genética aparece como la respuesta más válida en pro de los derechos de las mujeres, aun cuando un registro de violadores es completamente ajeno (e incluso antagoniza) con las demandas del movimiento feminista local:

5 Según lo establecido en una declaración del Ministerio de Seguridad (Resolución 439-E/2017) se utiliza como motor del registro el CODIS, software desarrollado por el departamento de investigación criminal de Estados Unidos (FBI).
Como sociedad y pueblo lamentablemente [...] nos juntamos en los puntos más históricos de la ciudad de Buenos Aires y en todos los puntos del interior del país para que se terminen las violaciones y muertes de mujeres y jóvenes que son el grupo más vulnerable, pero con este registro genético de violadores que firmó el decreto el presidente Mauricio Macri, es realmente el "Ni una menos". (Radio Latina FM 101.1, 2017, $\min .0: 38)^{6}$

Por su parte, la Ministra de Seguridad de la Nación, Patricia Bullrich, se presenta en sus declaraciones públicas como una clara defensora del uso de la genética en materia de resolución de delitos y de seguridad a nivel general, presentando "el ADN como huella digital del siglo XXI" (La Nación, 2019, párr. 2). Este Registro aparece, más que como un fin, como un punto de partida hacia el uso masificado de la genética en términos de seguridad y justicia.

Esta sintética recuperación de declaraciones y debates que subyacen a la aprobación y reglamentación del Registro visibilizan solo algunos de los múltiples actores, categorías y cuestionamientos que se articulan detrás de la creación del RNDG. El siguiente apartado se centrará en el uso de la genética en el discurso de los actores y las formas en que esta categoría es atravesada y puesta en diálogo con otras.

\section{Imaginarios en los discursos científicos, políticos y activistas}

Con imaginarios sociales se hace referencia a sistemas socialmente construidos que permiten percibir, explicar, interactuar e intervenir ante una porción de lo que socialmente se entiende por realidad. Según Castoriadis (1997), en cada uno de estos sistemas juegan ciertas "ontologías heredadas" que se convierten en puntos ciegos y que forman sólidos sentidos comunes instituyentes. Es así que múltiples categorías, tales como cuerpo, ciencia y delincuente, atraviesan los discursos sociales y sus definiciones pocas veces son problematizadas, tornándose verdades difícilmente cuestionables. Cada una de estas representaciones tiene efectos, adquiere sustrato, masa, cualidades y despierta variadas pasiones: en

6 Entrevista a Jorge Dotto. Programa Locutorio, Radio Latina, 24 de julio 2017. Disponible en https://www.youtube.com/ watch? $v=$ tPvtCcCgpAl y también en Programa Metadata en TN, 19 de julio de 2017, Disponible en https://www.youtube. com/watch? $v=S 4 m K-B u g 7 W k$ 
su conjunto, prefiguran acciones y creaciones en determinada época.

En este apartado se abordarán las definiciones de genética, violador y justicia que son usadas por los actores, para así indagar sobre algunos de los imaginarios que subyacen a la formulación del RNDG.

\section{Imaginarios en torno a la genética}

Los imaginarios sobre genética en Argentina se encuentran fuertemente permeados por las producciones y discursos de los organismos de derechos humanos, en donde los binomios genéticaidentidad, genética-memoria, genética-verdad y genética-justicia son reforzados a través de la difusión de los casos de la restitución de identidad de hijos apropiados durante la dictadura militar.

A su vez, existen distintas producciones culturales que buscan sensibilizar a la población sobre la importancia de acercarse al Banco de Datos Genéticos en caso de tener dudas sobre la propia identidad?. Podemos encontrar series — 99,99\%, La ciencia de las abuelas (2015), Televisión por la identidad (2007)—, películas — como La sangre no miente (2009), Verdades verdaderas (2011)—, diversas obras -en el marco del Teatro X La Identidad (desde el 2000 hasta la actualidad) - y una enorme cantidad de literatura, programas radiales y revistas que son parte de las narrativas que aportan metáforas insistentes en la idea de genética como identidad.

La asociación entre la genética y los organismos de derechos humanos a partir de la experiencia de la última dictadura aparece referenciada en el discurso de Isabel Yaconis, cuando narra cómo gestiona el pedido de ayuda por el caso de su hija:

A la primera persona que voy a conocer es Ana María Di Lonardo del Departamento de Genética del Hospital Durand, donde está el banco de ADN de personas que buscaban a sus hijos y

7 Es significativa la denominación de "restitución de identidad" que sintetiza la experiencia simbólica, legal, psicológica y social que se activa a partir de un cotejo genético positivo respecto a los familiares de los desaparecidos y su posterior comunicación a quienes se hicieron el estudio genético y a la sociedad en general. A su vez, presenta la paradoja del fundamento genético de la identidad y del parentesco dentro de los discursos de derechos de época que a su vez buscan desanclar de lo biológico dichas categorías señalándolas como convenciones culturales y diversas redes afectivas. nietos desaparecidos en la dictadura. Y ella me dice: "la gente dice que este es el banco de las abuelas, pero no es así, las abuelas consultan el banco". Ella hacía la salvedad de que su equipo había sido el encargado de crear el banco. Y sí, genética y justicia, una va de la mano de la otra. (Isabel Yaconis, 2019, min. 1:08)

La genética despierta pasiones en los discursos de los distintos entrevistados y habilita proyecciones de futuro e imaginación de posibilidades de lo más variadas.

Ya han sido mencionadas anteriormente las declaraciones de Bullrich sobre el ADN como elemento central del mecanismo de seguridad a futuro. Así mismo, las reiteradas referencias de Jorge Dotto, el director del RNDG, respecto al rol clave de la genética para terminar con los femicidios y la violencia sexual. Como se puede ver en el discurso de actores políticos (aunque no exclusivamente en ellos), las posibilidades que abre la genética como herramienta a futuro aparecen como un punto recurrente.

En un estudio sobre saberes de genética realizado por la Universidad de Michigan, tres de cada cuatro entrevistados creían posible que "las pruebas genéticas puedan usarse para predecir si una persona tendrá un infarto" (Cansino, 2003, p. 1). Por ahora ni se vislumbra en el horizonte próximo ninguna prueba genética que permita hacerlo. Sin embargo, la confianza que despierta la genética es ilimitada. Las palabras de Yaconis ilustran esta relación entre el imaginario sobre la genética y los efectivos desarrollos en dicha materia:

Cuando mi hija mayor me llama y me dice "mamá, va a haber ADN", yo al ADN lo conocí por mis hijas en el secundario o de la tele, porque no era de mi época el ADN, ay Diooos, entonces ya está, yo creí que en dos meses lo encontrábamos [refiriéndose al asesino de la hija]. (Isabel Yaconis, 2019, min. 39:40)

Como lo expresa la cita, estos imaginarios son complementados por representaciones provenientes de los consumos culturales asociados con la ciencia ficción y el thriller policial, que tienden a reforzar la idea de la genética como un saber infalible que da respuestas a los misterios y dramas que de otros modos no se han logrado resolver. A su vez, estos imaginarios tienden a asociar la tecnología genética con lo neutral y desideologizado. El propio cuerpo 
de la ley recupera estos imaginarios de objetividad y justicia para la reglamentación del Registro:

... siendo la individualización genética la herramienta más eficaz y certera usada para la identificación criminal [...] pues permite no solo concretar imputaciones penales sino también desincriminar a personas erróneamente acusadas, por resultar un método altamente objetivo y confiable de análisis, investigación e identificación. (Decreto 522/2017, 2017, párr. 7)

A su vez, estas producciones refuerzan las ideas de que se trata de un saber experto que se desarrolla en complejos laboratorios de la mano de un exclusivo grupo de especialistas. Al respecto, entrevistando a uno de los desarrolladores del motor de búsqueda GENis, este aclara:

Con todo este tema de las series de televisión hay como una obnubilación con este tipo de evidencia, digamos. Porque los números son muy Ilamativos. Hay probabilidad de 0,00001 de que este match lo tenga otra persona. Pero ponele en un caso de violación, si vos vas y hacés un isopado vaginal o lo que fuera, puede ser [que se encuentre material biológico] del novio o lo que fuera... Hay que ponderar esas cosas. Es un aporte más, no es una pericia. (Entrevista 2, 2019, min. 27:10)

Acompañado de las contundentes cifras probabilísticas, otro elemento recurrente en el discurso de todos los entrevistados es que la genética puede suscitar ciertas preocupaciones:

Si vas a un juicio y hay un ADN y da 99,99 es irrefutable porque a mí me lo dijeron los genetistas. Sos o no sos. Si da 99,98 ya es sospechoso para la justicia. Este es un ADN mudo. (Isabel Yaconis, 2019, min. 38:40)

Es así que Yaconis recupera, a partir de su reafirmación de la eficacia de la muestra de ADN, las preocupaciones y tensiones que se presentan en torno a las potencialidades de la tenencia de información de tipo genético. Otro actor entrevistado, uno de los impulsores del proyecto GENis desde la Fundación Sadosky, hace eco de esta preocupación al afirmar:

No es todo el genoma, es solamente una partecita para individualizar de manera inequívoca a una persona. Esto es importante porque el ADN codificante es la[el] que contiene información muy delicada que responde a los patrones de riesgo sanitario, cuál es la carga que una persona trae en su ascendencia y la propensión a contraer enfermedades que trae cada uno. (Entrevista 3, 2019, min. 14:06)

Reforzando esta tensión se encuentra el ya mencionado doctor en ciencias físicas, quien comenta que para la toma del perfil genético se obtiene el ADN completo, lo que no deja de ser "un acto de fe", que los laboratorios recorten solo los marcadores necesarios y no analicen, conserven o vendan la parte restante. Al respecto, refiere a un caso de un laboratorio médico que fue a juicio por venta de información genética y bromea sobre un mundo como el del film Gattaca ${ }^{8}$.

Es así que los imaginarios en torno a la genética también pueden ser aterradores y tenebrosos, incluso —o más aún- para los especialistas en la materia:

El uso de la genética llega hasta donde quieras. Es espeluznante lo que se puede hacer. Vos confías que les estás dando una herramienta a la justicia. Eso es lo que a fin de cuentas te tiene que tranquilizar. Pero es una herramienta súper poderosa, por eso tiene que estar muy claro la integridad de los datos. Que los datos no salgan, que los datos no sean alterables. Que lo que se dice que se va a hacer con esos datos sea lo que haga. (Entrevista 2, 2019, $\min .32: 48$ )

Así afirma el físico del equipo creador del GENis, quien horas después de ser entrevistado, aportó páginas de servicios de reconstrucción de características faciales (como color de ojos, piel, cabello) a partir de la información del ADN a modo de ejemplificar estas potencialidades. La posibilidad de presuponer, a partir de rastros de ADN, el origen geográfico o las características fenotípicas del criminal no identificado es una práctica habitual en Francia respecto a los violadores, tomando las investigaciones de Vailly (2018). Aunque también se ha utilizado en el marco de varios centenares de investigaciones policiales en los Estados Unidos y en el caso de los atentados terroristas de Madrid en 2004, tal como lo describe Sankar (2010).

8 Gattaca es una película de ciencia ficción-drama del 1997 referente a la manipulación genética; creando válidos e inválidos, a los que se les preasigna un trabajo u otro por su condición genética. 
De la mano con estos señalamientos, aparece la seguridad informática como un tema de debate. Como ya se ha mencionado, la repentina incorporación del Codis como software del RNDG despertó oposiciones principalmente asociadas con la pérdida el control de la información genética que se acumula en el Registro, y fue atravesada por un debate en torno a la soberanía de la información genética: el GENis, de producción nacional o el Codis, brindado como herramienta por parte del FBI. En referencia a esto, uno de los involucrados en el proyecto GENis desde la Fundación Sadosky comenta:

El Codis es gratuito y puede ser pensado como una acción de cooperación internacional del $\mathrm{FBI}$, pero lo cierto es que hay una devolución de la inversión. Es gratuito entre comillas. [...] En nuestro caso, la seguridad fue un requerimiento explícito de los fiscales de que esta información tiene que estar muy resguardada por riesgo a que termine como Wikileaks. (Entrevista 3, 2019, min. 48:09)

La importancia sobre el control, sobre el destino y los usos de la información aparece así como un elemento que se cruza con debates en torno a la soberanía y la importancia del desarrollo tecnológico nacional. Otro de los entrevistados explica al respecto:

Cuando nos preguntan por qué no usamos el software del FBI y hacemos el propio, es sobre todo por las implicancias de un tema tan sensible como es el ADN y usar un software que uno desconoce cómo funciona y que existe la posibilidad de que ese software instalado tenga lo que se llama una back door, una puerta trasera por la cual el proveedor toma todos los perfiles genéticos que uno carga y construye su propia base universal de datos genéticos. (Entrevista 2, 2019, $\min .12: 50$ )

Hasta aquí se ha reconstruido y recuperado la forma en que la genética aparece en los discursos de los diferentes actores, visibilizando su asociación con valoraciones, posibilidades y expectativas diversas que se entrecruzan.

La formulación del RNDG en el contexto ya detallado anteriormente no es casual. La creencia en la eficacia de la genética, como saber científico incuestionado, puede haber funcionado, entre otros elementos, como uno de los imaginarios que la convierten en componente necesario de una ley considerada deseable por diferentes actores. Su salida del laboratorio es habilitada por un contexto, pero también por un imaginario y expectativas determinadas.

\section{Imaginarios en torno a la figura del violador}

Un registro como el RNDG puede ser usado en dos situaciones. Por un lado, está estipulado que en el banco entre información genética de personas condenadas con sentencia firme por violación. Por otro lado, el Registro también sirve en el caso de que, frente a una denuncia de violación, se halle material del agresor anónimo que permita confeccionar un perfil genético para su cruce con otros perfiles y una futura identificación. Toda la información recolectada por el Registro está disponible para cuando una investigación judicial futura lo requiera. Ambos procedimientos posibles prefiguran al violador como sujeto que reincide. Solo es útil recolectar información genética de personas que han realizado violaciones en el caso de que se espere que vuelvan a reincidir en el delito.

Es decir, en la letra y procedimiento de ley del RNDG, el violador es un sujeto que reincide. Desde esa perspectiva, haber pagado su condena en la cárcel no lo exime, sino más bien exalta su peligrosidad, porque ya no está controlado por el encierro. Al respecto, Isabel Yaconis relata un caso ejemplar:

[...] Él estaba preso por violación a una chica de quince años [...] pero tenía los fines de semana porque él pedía salir, decía que era lutier, que lo había aprendido en un taller en la cárcel y entonces él se iba a reinsertar haciendo violines, iimaginate! [...]. Y un día que sabía que la chica estaba sola porque vivía en el piso de arriba, fue, le golpeó la puerta, intentó violarla en la cama de los padres y la terminó matando como de diecisiete puñaladas. (Isabel Yaconis, 2019, $\min .34: 42$ )

En el caso de Micaela García, antes mencionado, el agresor es otro representante paradigmático de esta concepción de violador. El hombre se encontraba preso por dos violaciones previas y, a partir de la evaluación del juez, le fueron concedidas salidas transitorias. En una de ellas, violó y asesinó a Micaela. 
Otro elemento que define la figura de violador estipulada por el RNDG es que este se supone desconocido para la víctima; así, el aporte de la genética aparece clave en la identificación del mismo. Sin embargo, según los datos del 2016 del programa "Las víctimas contra las violencias" del Ministerio de Justicia y Derechos Humanos, en el $75 \%$ de los casos de abuso sexual infantil el agresor es un familiar de la víctima, siendo el $40 \%$ de los casos el padre y el $16 \%$ el padrastro. Diversas mediciones coinciden que en los casos de víctimas adultas los causantes de la agresión sexual también son personas de autoridad del contexto de la víctima, generalmente exparejas, parejas y jefes.

A su vez, en los diferentes discursos recuperados se hace referencia a la monstruosidad del violador, como lo explica Tonkonoff (2013), como locus imaginario de todas las transgresiones, como una excepcionalidad social. En línea con ello, Jorge Dotto, director del RNDG, afirma en una entrevista radial: "Son criminales que tienen sentencia firme [...] es el perfil genético de la persona que haya cometido los actos delictivos más agresivos y más violentos y peores que puede cometer un ser humano" (Radio Latina FM 101.1, 2017, min. 1:42).

En torno a este punto, Sergio Tonkonoff (2017) propone un recorrido interesante por las propuestas de análisis realizadas por diferentes autores sobre la figura del delincuente: Durkheim, Bataille, Sartre y Foucault. Señala que, si bien cada uno de ellos parte de supuestos y llega a conclusiones disímiles, puede encontrarse un acuerdo subyacente en todos los enunciados: construyen al delincuente como pieza clave en la institución de la sociedad. El delincuente, ya sea como generador de reacciones que promueven la cohesión social, ya sea ocupando una función expiatoria o purgativa, ocupa un rol dentro de la dinámica de lo social.

En esta perspectiva de violador se niega cualquier posibilidad de tratamiento eficaz y arrepentimiento de parte del victimario. El sujeto es un violador y, como tal, se presupone que lo volverá a hacer. La peligrosidad radica en la persona — el violador solitario - y se pierde de vista el marco que habilita la violación (las estructuras patriarcales arraigadas, los cómplices, la impunidad, los que dudan de la palabra de la víctima) y las condiciones contextuales del victimario (las condiciones de vida y el acceso a posibilidades laborales, educativas, tratamientos médicos, etc.).
Desde los feminismos antipunitivistas de Norteamérica, y siguiendo a Human Right Watch (2007), se señala que las experiencias de bancos genéticos redundan en el alejamiento del sistema de salud y de empleos formales de las personas registradas por agresión sexual (que ya han cumplido su condena), dado el posible carácter reestigmatizante de los estudios de sangre. Desde estas corrientes se resalta el potencial discriminador de estas políticas, en tanto hay una segmentación racial y de clase en lo que el sistema puede leer y codificar, porque son solo determinados cuerpos los que ingresan a las cárceles y, por ende, al registro genético. Estos cuerpos son los que aparecen como el espacio de prueba legitimado. La incursión de la genética como herramienta de seguridad empieza con menor cuestionamiento por los sujetos catalogados como delincuentes/violadores.

Resulta interesante observar la forma en que determinados imaginarios, previos a la formulación del RNDG, funcionan como piezas claves que prefiguran la forma que adquiere una ley. Es una idea determinada de violador sobre la cual se construye la normativa y, a la vez, son determinados imaginarios construidos en torno a la genética los que la sitúan como una herramienta necesaria en la búsqueda de justicia.

\section{Imaginarios en torno al acceso a la justicia}

La Ley 26.879 funciona a partir de determinados sentidos comunes en torno al acto sexual violento y a la gestión del hecho para acceder a la justicia. La denuncia de la violación debe ser inmediata: según este imaginario, la víctima de violencia sexual ni siquiera se da un baño, va directo a hacer la denuncia y a realizarse un isopado, así no se contamina o se pierde el material genético dejado por el violador.

Uno de los entrevistados del equipo de implementación del software de "matcheo" genético del BNDG comentaba cómo una adolescente fue obligada a practicarle sexo oral a su agresor y ella tuvo la lucidez de limpiarse el semen con una prenda que luego llevó a la fiscalía como prueba en el momento en que decidió hacer la denuncia.

Dentro del imaginario recuperado por el RNDG, la violación es la que deja signos evidentes de la agresión. Ya no solo se exigirán a la víctima marcas físicas de forcejeo, desgarros, rasguños, sino que 
también se requieren restos biológicos que aporten ADN del agresor: semen, pelos, sangre, saliva, orina y sobre todo tejido epitelial que vuelvan a dar cuenta de que la víctima ha resistido el acto.

Con el Registro de Violadores, la huella material del crimen pasa a sobreponerse al testimonio de la víctima. Es el ADN el que testimonia, a partir de una prueba irrefutable, precisa, objetiva. Recordemos que la comparación entre el accionar del Registro y el de las marchas de "Ni una menos" es una mención recurrente en los discursos públicos del director del Registro, Jorge Dotto, quien delimita un encuadre para la expresión y gestión de la experiencia en torno a la violencia sexual, no solo de la víctima, sino que también propone los repertorios de acción más "sensatos" (que no son colectivos ni en el espacio público) a partir de un caso de violencia sexual.

\section{ADN: entre el cuerpo y la información}

Queda por estudiar de qué cuerpo tiene necesidad la sociedad actual.

M. Foucault (1980, p. 105)

El ADN es comprendido de muchas formas en las referencias de los entrevistados y en la bibliografía: como transmisión biológica, como unidad elemental de lo viviente, como identidad, como memoria portátil de la historia de vida, como herencia y a la vez como proyecto. Pero siempre está anclado, sostenido e inscripto en la biomateria, es decir, en el cuerpo.

Para la toma de muestra de ADN, tanto para el RNDG como para estudios de laboratorios privados, de compatibilidad genética entre matrimonios $u$ otras experiencias de bancos genéticos internacionales, se solicita un hisopado en la mejilla para extraer una muestra de saliva. En medio de una conversación, Isabel Yaconis, saca de su cartera un kit de toma de muestra genética. Dice que no sale sin él, que lo exhibe en todos lados y que "a la gente le encanta". Cuenta que le sirve para explicar la simpleza del procedimiento. Distinto es el mecanismo elegido por el Banco de Datos Genéticos fundado por las Abuelas de Plaza de Mayo, que trabajan a partir de una muestra de sangre y que lo expresan a través del lema del banco "Esa gota de sangre es una gota de esperanza".
Es que los fluidos corporales son líquidos poderosos. Siguiendo a Catoggio (2016) y Vecchioli (2018), podemos constatar que, a lo largo de la historia, la sangre ha sabido transmitir herencias, linajes, trayectorias políticas, identidades, derechos y patrimonios. Así como la sangre, podríamos estar hablando de otros elementos (saliva, semen, piel, etc.) en los que se materializan esos imaginarios.

Nos encontramos así frente a una situación particular. Ya no podemos existir sin dejar rastros de nuestro cuerpo por doquier. Perdemos cabellos, piel, saliva; cuando tocamos, transpiramos, vamos marcando nuestros espacios y relaciones, impregnando todo con nuestro ADN. Esto es comprendido por quienes ven en los bancos genéticos una herramienta contundente. En una escena en donde no hay personas identificables a simple vista, es posible reconstruir un pasado a partir de diferentes huellas, encontrar elementos que remiten a cuerpos que ya no están del todo presentes ${ }^{9}$.

Martínez Barreiro (2004) señala que el cuerpo pierde su unidad al ser invadido cada vez más por sistemas abstractos y conocimientos especializados, los cuales sitúan a las sociedades contemporáneas ante nuevos enigmas y también ante nuevos dilemas. En consonancia, Costa y Rodríguez (2010) hacen énfasis en las nuevas posibilidades que se abren a la creación y obtención de información. López (2002) señala que la tecnología genética quiebra la idea del cuerpo como unidad, lo fragmenta destruyendo su territorialidad. Al respecto, el científico del equipo desarrollador del motor de búsqueda GENis advertía: "Si yo tengo la información de tu genoma también la tengo de tu papá, de tu mamá, de tus primos, de tus hermanos. Puedo salir a buscarlos. Tu información no es tuya" (Entrevista 3, 2019, $\min$. 25:43).

Surgen preguntas tales como icuál es la forma en que se utilizan y se manejan estos nuevos caudales de información?, ¿cómo y quiénes (¿es acaso el Estado nacional?, ¿un organismo internacional?,

9 Esto despierta preguntas en torno a la estandarización de los mecanismos de toma de muestra genética en torno a la saliva o sangre. ipor qué de ese modo? ipor qué hay un objeto específico (kit de isopado, jeringa) proveniente de la tecnología biomédica, que media en la toma de la muestra cuando sabemos que no es necesario? ¿Por qué se precisa que un objeto ingrese a nuestro cuerpo para extraer la muestra? Como afirman con sorpresa Gatti y Anstett, "la sangre es aún hoy cuerpo" (2018). 
¿empresas de seguridad?, ¿laboratorios?, ¿cualquiera que lo pueda costear?) pueden usar estas nuevas herramientas?, ¿cómo afectan la privacidad?, ¿cómo se entrecruzan la información biológica y la razón securitaria?, ¿cuáles son las nuevas posibilidades de control, y de quién es la nueva información? A partir de los desarrollos genéticos, el cuerpo deja de ser lo visible, lo puramente material y pasa a ser “una máquina semiótica [...] así, el 'viejo' cuerpo humano es desarmado en su carne y rearmado en su información" (Rodríguez, 2019, p. 380).

Entender el cuerpo en tanto fuente de información es lo que, según Jorge Dotto, director del RNDG, permite comprender por qué el Registro es prácticamente infalible. Dedica bastante tiempo de su agenda a explicar en distintos programas masivos de radio, prensa y televisión, que todos los humanos nos diferenciamos por el 0,1 \% de nuestra composición genética, y esa diferenciación está compuesta por cuatro letras capaces de formular millones de combinaciones que no se repite en ninguna persona. Explica también que el Registro cuenta con un software especialmente desarrollado para procesar y "matchear" la enorme cantidad de información contenida en el ADN.

Las nociones de ADN como banco de datos compuesto por una combinación de letras alertan a Pablo Rodríguez sobre las resonancias religiosas en el modo en que vemos la naturaleza, en donde la metáfora va a ser la vida como un libro sagrado (escrito previamente a nosotros) a través de la genética contenida en forma de letras.

El ADN aparece así como un complejo banco de datos, por un lado, y por otro como comunicación sobre una memoria, un linaje y también un proyecto a futuro. El ADN es una fuente de tanta información que incluso se debe legislar sobre sus "secretos". Como aclara el Decreto Reglamentario 522/2017 del RNDG, en el artículo 11, "en ningún caso podrán ser utilizadas con fines discriminatorios ni estigmatizantes que vulneren la dignidad inherente a la persona humana, su intimidad, su privacidad y su honra".

Un "nuevo cuerpo", fragmentado y portador de un caudal cada vez mayor de información, plantea nuevos escenarios para los mecanismos de control, en este caso en manos del Estado. Ya Deleuze (2006), a fines del siglo XX, planteó la crisis frente a la cual se enfrentaban aquellas instituciones que ligaban vigilancia y encierro, característica de las sociedades disciplinarias. Hoy en día es posible tener información sobre un cuerpo sin necesidad del encierro físico de una persona en una cárcel e incluso sin necesidad de haber tenido contacto directo con aquel cuerpo como unidad visible.

Cabe preguntarse en este punto iqué es la seguridad tal y como se plantea la estrategia del RNDG? Esta ley traduce la seguridad en acumulación y procesamiento de información en un banco de datos. Michel Foucault (2006) diferenciaba los dispositivos disciplinarios de los de seguridad, y centraba una de sus principales diferencias en la relación con el espacio; mientras que los dispositivos disciplinarios encerraban para controlar, los de seguridad tendían a ampliarse, a actuar sobre el afuera, a trabajar sobre la realidad. La seguridad aparece como el pleno conocimiento de los hechos/cuerpos y se asocia con la tenencia de cada vez más información, en palabras de Rodríguez (2019), la captura del acontecimiento. Así, la seguridad y la vigilancia se tornan dos elementos indisociables.

En este cambio epistémico puede leerse la conformación del RNDG como un atisbo de las posibles configuraciones que pueden adoptar los mecanismos de control y vigilancia en las sociedades contemporáneas.

Es así que encontramos que no solo hay algunos imaginarios que prefiguraron el RNDG, tales como los sentidos atribuidos a la genética y la concepción de violador, sino que, en paralelo, otros están siendo puestos en cuestión y transformados por el mismo, tales como el de cuerpo, justicia y seguridad.

\section{CONCLUSIONES}

La propuesta de este artículo es pensar la genética como categoría que participa de diferentes debates sociales. Se partió del análisis del RNDG, los discursos de los actores participantes en su formulación y los contextos más amplios en los que se insertó su aprobación y reglamentación.

El RNDG se erige como una ley en la que se pueden encontrar diálogos e intersecciones entre diferentes imaginarios: en torno a la genética —asociada, entre otras cosas, a los derechos humanos, a la ciencia y a sus aportes técnicos-, otros en relación a la seguridad como política de Estado, a la tecnología como productora de objetividad y la dimensión moral para la sexualidad encarnada en la construcción 
de la figura de violador y de víctima. Estos son solo algunos de los sentidos que pueden rastrearse en el discurso de los actores, y que funcionaron como elementos que posibilitaron la formulación y desarrollo de la ley.

Múltiples actores, con diferentes trayectorias, incorporan a la genética como un elemento en sus discursos. El RNDG no solo se erige como la materialización de la relación entre la genética y su eficacia técnica, sino que también se construye sobre cierta constelación entre la figura del violador, el rol de la justicia, la denuncia y la víctima.

Pero, por otro lado, esta normativa también puede pensarse desde la novedad. Nociones tales como cuerpo y privacidad parecen redefinirse al verse atravesadas por una cantidad y centralidad mayor de los datos y de la información. La tecnología genética abre nuevas posibilidades, y con ellas devienen nuevos debates. El Estado aparece como un actor que debe dar respuesta y regular sobre ellos: el propio cuerpo de la ley que estipula la creación del RNDG establece límites para el uso de la información genética. En este marco pueden leerse los debates en torno a la soberanía de la información que suscitó el uso del Codis como software: ¿a quién pertenecen estos crecientes caudales de información?

La genética sale del laboratorio para constituirse en una herramienta de los mecanismos de seguridad del Estado y para habitar en el discurso de múltiples actores. En su incursión como categoría social, tiene el potencial de generar diálogos e intersecciones entre grandes marcos productores de discursos, imaginarios, nuevos dilemas y preguntas que tocan la puerta de las sociedades contemporáneas. 


\section{REFERENCIAS}

Arduino, I. (2014). Melina Romero. La mala víctima. Revista Anfibia (s.d.). http://revistaanfibia. com/ensayo/la-mala-victima

Arduino, I. (2018). Los peligros del punitivismo. Revista Los Inrockubtibles. Edición del mes de marzo. https://medium.com/los-inrockuptibles/feminismo-los-peligros-del-punitivismodf1e397bf885

Cansino, G. (2003). Imaginario genético. Revista Panace@: Asociación Internacional de Traductores y Redactores de Medicina y Ciencias Afines, 4(12). https://www.tremedica.org/wpcontent/uploads/n12_entremes_Casino.pdf

Castoriadis, C. (1997). El imaginario social instituyente. Revista Zona Erógena, 35 (9), p.1-9.

Catoggio, M. S. (2016). Los desaparecidos de la iglesia: el clero contestatario frente a la dictadura. Buenos Aires: Siglo Veintiuno Editores.

Costa, F. y Rodríguez, P. (2010). La vida como información, el cuerpo como señal de ajuste: los deslizamientos del biopoder en el marco de la gubernamentalidad neoliberal. Michel Foucault: biopolítica y neoliberalismo. Santiago de Chile: Editorial Universidad Diego Portales.

Deleuze, G. (2006). Post-scriptum sobre las sociedades de control. Polis. Revista Latinoamericana, 13, p.1-7.

Despentes, V. (2013). Teoría King Kong. Buenos Aires: Hekht Libros.

Foucault, M. (1980). Microfísica del poder. Madrid: La Piqueta.

Foucault, M. (2006). Clase del 11 de enero de 1978. En: Seguridad Territorio y Población, México D. F.: Fondo de Cultura Económica, p.15-44

Gatti, G. y Anstett, E. (2018). Sangres políticas. Athenea Digital, 18(1). Universidad del País Vasco.
Gil, A. S. (2017). Violencia de género y sentidos en la prensa argentina: Cobertura del femicidio de Ángeles Rawson. Revista Latinoamericana de Ciencias de la Comunicación, 14(27). https:// www.alaic.org/revista/index.php/alaic/article/view/1044

Hercovich, I. (2000). La violación sexual: un negocio siniestro. En: H. Birgin (comp.). Las trampas del poder punitivo. El género del derecho penal. Buenos Aires: Biblos.

Human Rights Watch (2007). No easy answers sex offender laws in the US. https://www.hrw. org/reports/2007/us0907/

ISAAA (2016). Resumen ejecutivo Situación Mundial de los Cultivos Biotecnológicos/GM Comercializados: 2016. Brief 52. https://www.isaaa. org/resources/publications/briefs/52/executivesummary/pdf/B52-ExecSum-Spanish.pdf

La Nación (2019). Patricia Bullrich: registro de ADN para todos: es la huella digital del siglo XXI". https://www.lanacion.com.ar/politica/ patricia- bullrich-registro-adn-todo-huelladigital-nid2223050

López Gómez, D. (2002). La virtualización del cuerpo y la investigación genética. Revista Athenea digital: Revista de Pensamiento e Investigación Social, 1, p.174-178.

Martínez Barreiro, A. (2004). La construcción social del cuerpo en las contemporáneas. Papers: Revista de sociología, 73, p. 127-152.

Penchaszadeh, V. (2018). La gesta de Abuelas demuestra que la ciencia puede y debe estar al servicio de los valores humanos fundamentales. Página 12. https://www.pagina12.com. ar/161704-la-gesta-de-abuelas-demuestraque-la-ciencia- puede-y-debe-es

Radio Latina FM 101.1 (2017). Jorge Dotto (Médico Genetista) en el \#Locutorio 
[video]. YouTube: https://www.youtube.com/ watch? $v=$ tPvtCcCgpAI

Rodríguez, P. (2019). Las palabras en las cosas. Saber, poder y subjetivación entre algoritmos y biomoléculas. Buenos Aires: Editorial Cactus.

Sankar, P. (2010). Forensic DNA Phenotyping: Reinforcing Race in Law Enforcement. In: Ian Whitmarsh \& David Sf. Jones (Eds.), What's the Use of Race? Modern Governance and the Biology of diference, . Cambridge, London: MIT Press, p. 49-61.

Sautu, R. (2006). Manual de metodología. Buenos Aires: Clacso.

Silvestri, L. (2017). Leonor Silvestri, enemiga pública. Revista Furias. http://revistafurias.com/ leonor-silvestri-enemiga-publica/
Tonkonoff, S. (2013). Homo violens. El criminal monstruoso según Georges Bataille. Revista Gramma, 23(49), p. 269-276.

Tonkonoff, S. (2017). Las funciones sociales del delincuente. Revista Ensambles, 1(7), p.71-81.

Vailly, J. (2018). Las políticas sobre el origen de los sospechosos en Francia (2006- 2014). Athenea Digital, 18(1), p. 33-49.

Vecchioli, V. (2018). Deserving victimhood: kinship, emotions and morality in contemporary politics. Vibrant: Virtual Brazilian Anthropology, 15(3). 